\title{
APPLICATION OF CENTRAL COMPOSITE DESIGN OPTIMIZATION TECHNIQUE FOR DETERMINATION OF COPPER IN FRUIT AND VEGETABLE SAMPLES WITH ADSORPTIVE STRIPPING VOLTAMMETRY IN THE PRESENCE OF CALCEIN
}

\author{
Deswati $^{1, *}$, Hamzar Suyani ${ }^{1}$, Izzati Rahmi ${ }^{2}$ and Hilfi Pardi ${ }^{1}$ \\ ${ }^{1}$ Department of Chemistry, Faculty of Mathematics and Natural Science, Andalas University, \\ Kampus Limau Manis, Padang25163, Indonesia \\ ${ }^{2}$ Department of Mathematics, Faculty of Mathematics and Natural Science, \\ Andalas University, Padang25163, Indonesia \\ *E-mail: deswati_ua@yahoo.co.id
}

\begin{abstract}
This study was to optimize the determination of copper by adsorptive stripping voltammetry (AdSV) in the presence calcein. The independent factors that affect the response were: calcein concentration, $\mathrm{pH}$, potential accumulation and time accumulation. The research design was used a central composite design (CCD) with 4 variables, 5 levels and 31 a combination of treatments. The first step of $2^{\mathrm{k}}$ factorial design optimization is: to give the highest level of code values (+1.68), the lowest level (-1.68) and code (0) as the center point. Programs were used for statistical data processing, Minitab 17. The obtained optimum conditions for the determination of copper were: calcein concentration $0.11 \mathrm{mM}, \mathrm{pH} 6.8$, potential accumulation $-0.88 \mathrm{~V}$ and time accumulation $42.34 \mathrm{~s}$. The RSD $0.74 \%$, recovery $99.88 \%$, the linear calibration graph for the concentration $(0.2-110.0) \mu \mathrm{g} / \mathrm{L}$, and the detection limits 1.79 $\mu \mathrm{g} / \mathrm{L}$. This procedure was applied for the determination of copper in the fruit and vegetable samples with satisfactory results.
\end{abstract}

Keywords: Optimize, copper, adsorptive stripping voltammetry, central composite design, fruit and vegetable samples

( ) RASĀYAN. All rights reserved

\section{INTRODUCTION}

Some of the elements included in the category of heavy metals such as $\mathrm{As}, \mathrm{Cr}, \mathrm{Cd}, \mathrm{Pb}, \mathrm{Fe}, \mathrm{Cu}, \mathrm{Co}, \mathrm{Hg}, \mathrm{Se}$, $\mathrm{Sb}, \mathrm{Mn}, \mathrm{Zn}$, and $\mathrm{Ni}$ come from industrial waste and the results of the activity of the population. Copper is essential for living organisms at only trace amounts, but when it exceeds the prescribed limit, it has also a detrimental effect on human health. Exposure to excessive levels of copper can result in a number of adverse health effects including liver and kidney damage, anemia, immunotoxicity, and developmental toxicity ${ }^{1}$. Therefore, due to applications of this element in chemical industry, it is very important to be able to determine of copper in fruit and vegetable samples with high sensitivity and selectivity. If it enters into the human body has a tendency to congregate in organs, could not get out again through the digestive process. Water, land, and air are the medium that can be used for the deployment of heavy metals into the environment. Broad-leafed plants, in addition, to absorb heavy metals from the soil can absorb heavy metals from the air.

The previous studies, it has been reported by various researchers in the world, some determination of $\mathrm{Cu}$, and $\mathrm{Cd}$ acid dithiosalisilate $2.2^{2}$, the simultaneous determination of $\mathrm{Pb}$ and $\mathrm{Cd}$ with morin ${ }^{3}$, the simultaneous determination of $\mathrm{Cu}$, and $\mathrm{Cd}$ in food samples and water types complexing agent were used for the analysis of the determination of metal ions either individually or simultaneously with AdSV. The simultaneous with luminol ${ }^{4}$, the simultaneous determination of $\mathrm{Cu}, \mathrm{Pb}, \mathrm{Cd}$, and $\mathrm{Zn}$ using murexide ${ }^{5}$, the simultaneous determination of $\mathrm{Cd}, \mathrm{Cu}$, and $\mathrm{Pb}$ with calcon ${ }^{6}$, the simultaneous determination of $\mathrm{Pb}$, and $\mathrm{Cd}$ 
in natural waters with pyrogallol $\mathrm{red}^{7}$, the simultaneous determination of $\mathrm{Cu}, \mathrm{Pb}, \mathrm{Cd}, \mathrm{Ni}, \mathrm{Co}$, and $\mathrm{Zn}$ in bioethanol fuel with a mixture of several as a complexing agent by AdSV and regression multi-variant ${ }^{8}$, and the simultaneous determination of $\mathrm{Pb}, \mathrm{Cd}$, and $\mathrm{Zn}$ using clioquinol ${ }^{9}$, the simultaneous determination of $\mathrm{Cd}, \mathrm{Cu}, \mathrm{Pb}$ and $\mathrm{Zn}$ using calcein ${ }^{10}$, and the simultaneous determination of $\mathrm{Cu}, \mathrm{Pb}$ and $\mathrm{Cd}^{11}$. The determination is very sensitive to a number of $\mathrm{Cu}$ in food samples with 1.10 fenantrolin by AdSV ${ }^{12}$, and the determination of $\mathrm{Cu}$ in food samples with thiosemicarbazide ${ }^{4}$.

AdSV was selected as an alternative method because it has many advantages such as high salinity of the seawater does not interfere with the analysis, high sensitivity, detection limit low on the scale $\mu \mathrm{g} / \mathrm{L}$, simple sample preparation, rapid analysis, low infrastructure cost ${ }^{13-19}$. In addition to this method, it is possible to learn chemical species of heavy metals ${ }^{20-21}$, which can not be done with other methods. From the previous research, to find the optimization the determination of metal ions $\mathrm{Cd}, \mathrm{Cu}, \mathrm{Pb}$ and $\mathrm{Zn}^{6,13}$, and metal ions $\mathrm{Fe}, \mathrm{Co}, \mathrm{Ni}$, and $\mathrm{Cr}^{16}$ either in the form of single or simultaneous AdSV, carried out by observing the effect of one variable is changed, while the other variables are kept at a constant level. This optimization technique is called optimization of the variables or the factors at the current time.

The main drawback of the results of the optimization of the factors that such optimization does not take into account the effect of the interaction between the variables studied. Therefore, this technique does not describe the full effect on the response parameter ${ }^{24}$. Another disadvantage of the optimization of the factors is the increased number of trials required to do research, which leads to increased time and increased consumption of reagents and materials. To overcome this problem, a technique of optimization of analytical procedures is by using multivariate statistical techniques. Calcein was selected as a sensitive and selective as a complexing agent has been reported by Marcin and Golimowski ${ }^{25}$ on the determination of $\mathrm{Ti}$, but calcein used in the determination of $\mathrm{Cu}$ with optimization central composite design has not been reported. AdSV is a highly sensitive technique, the response obtained in the form of the peak current (Ip) was influenced by variables the following, namely: the effect variations of calcein concentration, $\mathrm{pH}$, potential accumulation and the time accumulation ${ }^{5-6,11,13-19}$. Therefore it is very important to determine the optimization of these parameters, which will affect the measurement of the peak current in order to improve the quality of analytical results ${ }^{24}$. The research design was used in this study. as a tool for optimization was: CCD with 4 is coding. where the value of the highest level (+1.68). the lowest level ($1.68)$ and code $(0)$ as the center point, 4 variables, 5 levels/degree and 31 a combination of treatments. The first step of $2^{\mathrm{k}}$ factorial design optimization programs for statistical data processing Minitab 17 by using RSM (Response Surface Methodology), The use of RSM has been reported by Yilmaz et al. ${ }^{27}$ in the determination of $\mathrm{Al}$ content in salt samples using calcon in AdSV. Furthermore, Phaollicci et al. ${ }^{26}$ have used the experimental design in the form of CCD optimization for determination of In(III) in the AdSV using pyrrolidine ammonium dithiocarbamates (APDC). Danielle et $\mathrm{al}^{8}$ have reported the simultaneous determination of $\mathrm{Cu}, \mathrm{Pb}, \mathrm{Cd}, \mathrm{Ni}, \mathrm{Co}$, and $\mathrm{Zn}$ in the AdSV using multivariant regression aided optimization techniques with projection algorithm (SPA-MLR). Espada-Bellido ${ }^{26}$ have used multivariant analysis for optimization determination of lead in the water AdSV at nanomolar levels based on the formation of metal complexes with 2-asetilpiridin salicyl hydrazone (2-APS). Deswati et al. ${ }^{29}$ have been using CCD for the determination of cadmium in seawater using calcon by AdSV and optimization determination and $\mathrm{Zn}$ in water samples. Furthermore, Deswati et al. ${ }^{30}$ have reported CCD for optimization of a lead with calcon as a complexing agent by AdSV. The purpose of this study was to obtain the optimum condition of $\mathrm{Cu}$, so can be applied to analyze in fruit and vegetable samples. To achieve these objectives, required an optimization technique that was using the analytical procedure RSM withCCD ${ }^{29-33}$. To determine the accuracy, precision, and sensitivity of the method are determined relative standard deviation (RSD), recovery and the limit of detection and the linearity of the proposed method.

\section{EXPERIMENTAL}

\section{Chemicals and Reagents}

The chemicals and reagents were used in this research: $\mathrm{Cu} 1000 \mathrm{mg} / \mathrm{L}$ (E. Merck), $\mathrm{CH}_{3} \mathrm{COONa}_{3} \mathrm{H}_{2} \mathrm{O}$ (E. Merck), $\mathrm{CH}_{3} \mathrm{COOH} 100 \%$ (E. Merck), $\mathrm{NH}_{4} \mathrm{Cl} .3 \mathrm{H}_{2} \mathrm{O}$ (E. Merck), $\mathrm{NH}_{4} \mathrm{OH} 100 \%$ (E. Merck), $\mathrm{KCl}$ (E. Merck), doubly distilled water, $\mathrm{HNO}_{3} 65 \%$ (E. Merck) 


\section{Apparatus and Instrumentations}

The instruments were used in this study were 797 Metrohm Computrace with HMDE working electrode, reference electrode such as $\mathrm{Ag} / \mathrm{AgCl} / \mathrm{KCl}$, a Pt electrode as a supporting electrode, $\mathrm{pH}$ meter 80 models Griffin. Griffin \& George Loughborough, England, and analytical balance Mettler AE 200, Toledo OHUSA, and glassware used in the laboratory.

\section{Work procedures}

Voltammeter into the vessel, put $10 \mathrm{~mL}$ of a standard solution of $\mathrm{Cu} 10 \mathrm{ug} / \mathrm{L}$, added $0.2 \mathrm{~mL}$ and $0.2 \mathrm{~mL}$ of $0.1 \mathrm{M} \mathrm{KCl}$ calcein in $20 \mathrm{~mL}$, this variable is set constant during the experiment. The concentration of calcein, $\mathrm{pH}$, accumulation potential and accumulation time are set according to the experimental design of the CCD in Table 1. From Table 1 is obtained peak current response of metal ions $\mathrm{Cu}$.

\section{Design of Research}

The design of the study was: CCD with RSM 4 factors and 5 levels of each factor is coded $-1.68,0$ and +1.68 with 2 replications. Score -1.68 indicates the value of the lowest variable, +1.68 figures show the highest variable values, and the number 0 indicates the value of the variable medium. Factors of the research design were the concentration of calcein, $\mathrm{pH}$, accumulation potential, and accumulation time. The statistical data processing program for the Minitab 17 using RSM.

\section{Sample Preparation}

Vegetable samples used in this study are cauliflower, mustard greens, eggplant, and broccoli, while the fruits used include apples, banana kepok, melon and dragon fruit. Samples of vegetables and fruits for the determination of copper metal content is determined first the water content, then do wet destruction with the addition of nitric acid pa and perchloric acid pa.

Each sample of $0.5000 \mathrm{~g}$ was carefully weighed and mashed, put into a Kestergum digestion flask. Further, the wet was destructed by the addition of $5 \mathrm{ml}$ of concentrated nitric acid and $0.5 \mathrm{ml}$ of concentrated perchloric acid, shaken and left overnight. Next, heated to the digestor block starting at $100^{\circ} \mathrm{C}$, after the yellow vapor is exhausted the temperature is increased to $200^{\circ} \mathrm{C}$. The destruction is terminated when the white vapor and liquid in the flask remain about $0.5 \mathrm{~mL}$, cooled and diluted with doubly distilled water and the volume is adjusted to $50 \mathrm{~mL}$, shaken until homogeneous and left overnight and disarrayed ${ }^{33}$.

The Clear solution is ready to be determined by copper metal content with Voltammeter and Atomic Absorption Spectrophotometer as a comparison. The determination of the optimum conditions used in this study is the procedure developed by the previous research team ${ }^{4,7-9,11-12,16-19}$.

Table-1: Design experiments RSM for determination of trace copper

\begin{tabular}{c|c|c|c|c|c}
\hline \multirow{2}{*}{ Run } & \multicolumn{3}{|c|}{ Factors } & Response \\
\cline { 2 - 5 } & Calcein concentration $(\mathrm{mM})$ & $\mathrm{pH}$ & Potential(V) & Time (s) & $(\mathrm{Ip})$ \\
\hline 1 & 0.1 & 6 & -1.0 & 30 & 288.67 \\
\hline 2 & 0.1 & 6 & -0.8 & 30 & 289.30 \\
\hline 3 & 0.1 & 6 & -1.0 & 70 & 304.30 \\
\hline 4 & 0.1 & 6 & -0.8 & 70 & 318.07 \\
\hline 5 & 0.1 & 8 & -1.0 & 30 & 340.83 \\
\hline 6 & 0.1 & 8 & -0.8 & 30 & 349.40 \\
\hline 7 & 0.1 & 8 & -1.0 & 70 & 155.48 \\
\hline 8 & 0.1 & 8 & -0.8 & 70 & 152.32 \\
\hline 9 & 0.3 & 6 & -1.0 & 30 & 105.23 \\
\hline 10 & 0.3 & 6 & -0.8 & 30 & 120.92 \\
\hline 11 & 0.3 & 6 & -1.0 & 70 & 147.02 \\
\hline 12 & 0.3 & 6 & -0.8 & 70 & 152.42 \\
\hline 13 & 0.3 & 8 & -1.0 & 30 & 235.45 \\
\hline
\end{tabular}


RASĀYAN $J$. Chem.

Vol. 10 | No. 4 |1359-1367 | October - December | 2017

\begin{tabular}{c|c|c|c|c|c}
\hline 14 & 0.3 & 8 & -0.8 & 30 & 228.63 \\
\hline 15 & 0.3 & 8 & -1.0 & 70 & 371.66 \\
\hline 16 & 0.3 & 8 & -0.8 & 70 & 256.74 \\
\hline 17 & 0.2 & 7 & -0.9 & 50 & 365.33 \\
\hline 18 & 0.2 & 7 & -0.9 & 50 & 365.40 \\
\hline 19 & 0.2 & 7 & -0.9 & 50 & 366.05 \\
\hline 20 & 0.2 & 7 & -0.9 & 50 & 366.30 \\
\hline 21 & 0.2 & 7 & -0.9 & 50 & 365.20 \\
\hline 22 & 0.2 & 7 & -0.9 & 50 & 361.74 \\
\hline 23 & 0.2 & 7 & -0.9 & 50 & 361.45 \\
\hline 24 & 0.04 & 7 & -0.9 & 50 & 289.45 \\
\hline 25 & 0.2 & 5.4 & -0.9 & 50 & 227.51 \\
\hline 26 & 0.2 & 7 & -1.06 & 50 & 245.17 \\
\hline 27 & 0.2 & 7 & -0.9 & 18.1 & 212.28 \\
\hline 28 & 0.36 & 7 & -0.9 & 50 & 243.76 \\
\hline 29 & 0.2 & 8.6 & -0.9 & 50 & 300.23 \\
\hline 30 & 0.2 & 7 & -0.74 & 50 & 312.72 \\
\hline 31 & 0.2 & 7 & -0.9 & 81.9 & 311.31 \\
\hline
\end{tabular}

\section{Detection Method}

The procedure of determining RSD (relative standard deviation), LOD (limit of detection), LR (linear range) and recovery has been done by previous researchers The procedure of determining RSD (relative standard deviation), LOD (limit of detection), LR (linear range) and recovery has been done by previous researchers. ${ }^{4,7-9,11-12,16-19}$

\section{RESULTS AND DISCUSSION}

\section{Optimization of Copper Using One Variable}

The optimization by observing the effect of one variable in the determination of $\mathrm{Cu}$ in the presence of calcein has been done ${ }^{17}$. The optimum condition as follow: calcein concentration $0.7 \mathrm{mM}, \mathrm{pH} 7$, accumulation potential $-0.6 \mathrm{~V}$, accumulation time $50 \mathrm{~s}$. At the optimum conditions, the relative standard deviation was obtained with 10 replicates $(\mathrm{n}=10)$ measurements standard solution $\mathrm{Cu}(\mathrm{II}) 10 \mathrm{ug} / \mathrm{L}$ was $0.86 \%$, respectively. This technique does not describe the full effect on the response parameters and optimization of these factors is the increase in the number of trials required to do research, which leads to increased time and increased consumption of reagents and materials. Therefore to overcome this problem, an optimization technique of analytical procedures is by using CCD.

\section{Optimization CCD for the determination of Copper}

The first order model can not be used. then proceed with the second order model by adding a quadratic effect and interaction. The result of data processing the model obtained the following:

$$
\begin{aligned}
\hat{y}=362.610- & 30.342 x_{1} \\
& +22.480 x_{2}+1.513 x_{3}+3.054 x_{4}-31.944-32.908 x_{2}^{2}-27.581 x_{3}^{2} \\
& -33.643 x_{4}^{2}+48.076 x_{1} x_{2}-7.529 x_{1} x_{3}+35.977 x_{1} x_{3}-9.489 x_{2} x_{3} \\
& -20.987 x_{2} x_{4}-7.311 x_{3} x_{4}
\end{aligned}
$$

Whereas the results of analysis of various experimental data can be seen in Table- 2 . Table- 2 carried out the test procedures to second order model. This hypothesis test was used to test the truth of the regression model, the test if there is a free variable (including quadratic and interaction effects) significantly influence the response variable. The hypothesis being tested is:

$\mathrm{H}_{0}: \beta_{\mathrm{i}}=0$.

$\mathrm{H}_{1}: \beta_{\mathrm{i}} \neq 0 ; i=1,2, \ldots, k$ 


\section{RASĀYAN J. Chem.}

Vol. 10 | No. 4 |1359-1367 | October - December | 2017

Table-2, the test regression parameters simultaneously produce a $p$-value of 0.000 , meaning that the $\mathrm{p}$ value obtained is smaller than the significance level used in the amount of $\alpha=0: 05$. Thus it was decided to reject Ho and conclude that the independent variable significant effect on the response variable, so that the second-order model is accepted.

Table-2: Results of Analysis of Variance the Second Order Model

\begin{tabular}{l|l|l|l|l|l|l}
\hline Source & DF & Seq SS & Adj SS & Adj MS & F & $P$ \\
\hline Regression & 14 & 176846 & 176846 & 12631.8 & 6.62 & $0.000(\mathrm{~S})$ \\
\hline Linear & 4 & 31136 & 31136 & 7783.9 & 4.08 & 0.018 \\
\hline $\mathrm{X}_{1}$ & 1 & 19939 & 19939 & 19938.9 & 10.44 & $0.005(\mathrm{~S})$ \\
\hline $\mathrm{X}_{2}$ & 1 & 10945 & 10945 & 10945.0 & 5.73 & 0.029 \\
\hline $\mathrm{X}_{3}$ & 1 & 50 & 50 & 49.6 & 0.03 & 0.874 \\
\hline $\mathrm{X}_{4}$ & 1 & 202 & 202 & 202.0 & 0.11 & 0.749 \\
\hline Square & 4 & 77769 & 77769 & 19442.3 & 10.18 & 0.000 \\
\hline $\mathrm{X}_{1} * \mathrm{X}_{1}$ & 1 & 22839 & 17096 & 17096.3 & 8.95 & $0.009(\mathrm{~S})$ \\
\hline $\mathrm{X}_{2} * \mathrm{X}_{2}$ & 1 & 21698 & 18145 & 18144.9 & 9.50 & $0.007(\mathrm{~S})$ \\
\hline $\mathrm{X}_{3} * \mathrm{X}_{3}$ & 1 & 14268 & 12745 & 12745.1 & 6.68 & 0.020 \\
\hline $\mathrm{X}_{4} * \mathrm{X}_{4}$ & 1 & 18964 & 18964 & 18964.0 & 9.93 & $0.006(\mathrm{~S})$ \\
\hline Interaction & 6 & 67941 & 67941 & 11323.5 & 5.93 & 0.002 \\
\hline $\mathrm{X}_{1} * \mathrm{X}_{2}$ & 1 & 36981 & 36981 & 36980.9 & 19.37 & $0.000(\mathrm{~S})$ \\
\hline $\mathrm{X}_{1} * \mathrm{X}_{3}$ & 1 & 907 & 907 & 906.9 & 0.47 & 0.501 \\
\hline $\mathrm{X}_{1} * \mathrm{X}_{4}$ & 1 & 20710 & 20710 & 20709.8 & 10.85 & $0.005(\mathrm{~S})$ \\
\hline $\mathrm{X}_{2} * \mathrm{X}_{3}$ & 1 & 1441 & 1441 & 1440.8 & 0.75 & 0.398 \\
\hline $\mathrm{X}_{2}{ }^{*} \mathrm{X}_{4}$ & 1 & 7047 & 7047 & 7047.2 & 3.69 & 0.073 \\
\hline $\mathrm{X}_{3} * \mathrm{X}_{4}$ & 1 & 855 & 855 & 855.3 & 0.45 & 0.513 \\
\hline Residual Error & 16 & 30547 & 30547 & 1909.2 & & \\
\hline Lack-of-Fit & 10 & 30523 & 30523 & 3052.3 & 746.11 & 0.000 \\
\hline Pure Error & 6 & 25 & 25 & 4.1 & & 0.000 \\
\hline Total & 30 & 207393 & & & & \\
\hline
\end{tabular}

\section{Determination of Stationary Point}

Based on the regression coefficients in Table 2 can be arranged matrix B and B as follows:

$$
b=\left[\begin{array}{r}
-30.3417 \\
22.4800 \\
1.5131 \\
3.0543
\end{array}\right] \text { and } B=\left[\begin{array}{cccc}
-31.9435 & 24.0380 & -3.7643 & 17.9886 \\
24.0380 & -32.9085 & -4.7447 & -10.4934 \\
-3.7643 & -4.7447 & -27.5806 & -3.6557 \\
17.9886 & -10.4934 & -3.6557 & -33.6431
\end{array}\right]
$$

in order to obtain a stationary point as follows:

$$
x_{0}=-\frac{B^{-1} b}{2}=\left[\begin{array}{c}
-0.876403 \\
-0.210201 \\
0.233981 \\
-0.383074
\end{array}\right]
$$

thus, the response to a stationary point solution is obtained as follows:

$$
\hat{y}=\hat{\beta}_{0}+\frac{1}{2} x_{0} b=36210+10.5251=373.135
$$


RASĀYAN J. Chem.

Vol. 10 | No. 4 |1359-1367 | October - December | 2017

Furthermore, the stationary point can be restored to the true value, acquired conditions that provide the optimal solution is as follows:

Table-3: Results the optimum conditions of $\mathrm{Cu}$ with RSM

\begin{tabular}{l|c|c}
\hline Variable & $\begin{array}{c}\text { Optimal value (with } \\
\text { coding) }\end{array}$ & $\begin{array}{c}\text { Optimal value } \\
\text { (without coding) }\end{array}$ \\
\hline $\mathrm{X}_{1}($ Conc.calcein) & -0.876403 & 0.112360 \\
\hline $\mathrm{X}_{2}(\mathrm{pH})$ & -0.210201 & 6.78980 \\
\hline $\mathrm{X}_{3}($ Potential $)$ & 0.233981 & -0.876602 \\
\hline $\mathrm{X}_{4}$ (Time) & -0.383074 & 42.3385 \\
\hline
\end{tabular}

Characteristics of Response Surface Analysis

Furthermore, the stationary point can be restored to the true value, acquired conditions that provide the optimal solution is as follows:

To get an idea of the characteristics of the surface of the first response calculating eigenvalues $(\lambda)$ of the matrix $B$ and obtained:

$\lambda=[-68.4096-29.5170-23.3413-4.8078]$

Fourth eigenvalues are negative, then the shape of the surface response is maximum. It can also be seen from the plot contour and response surface plot. By making constant two among the 4 factors were observed at a stationary point, then it may be possible to plot the contour and response surface as shown in Fig.-1.

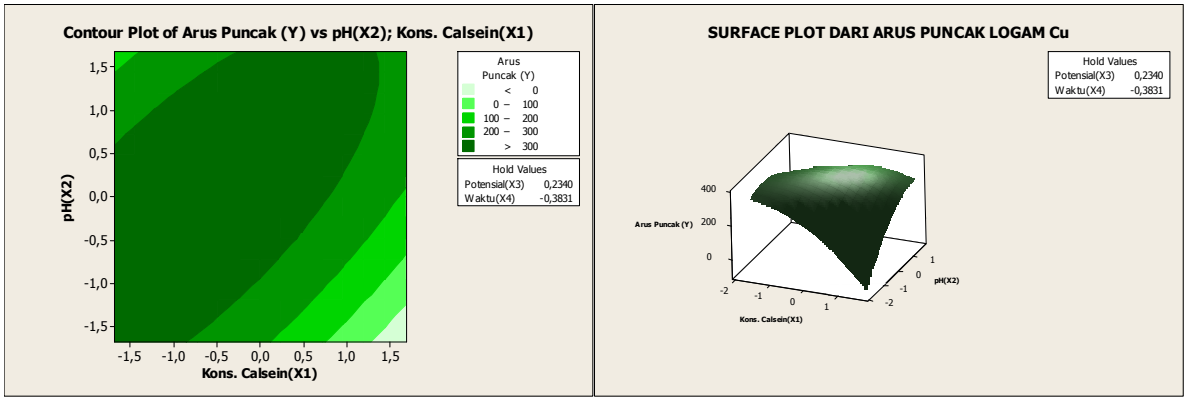

(a)

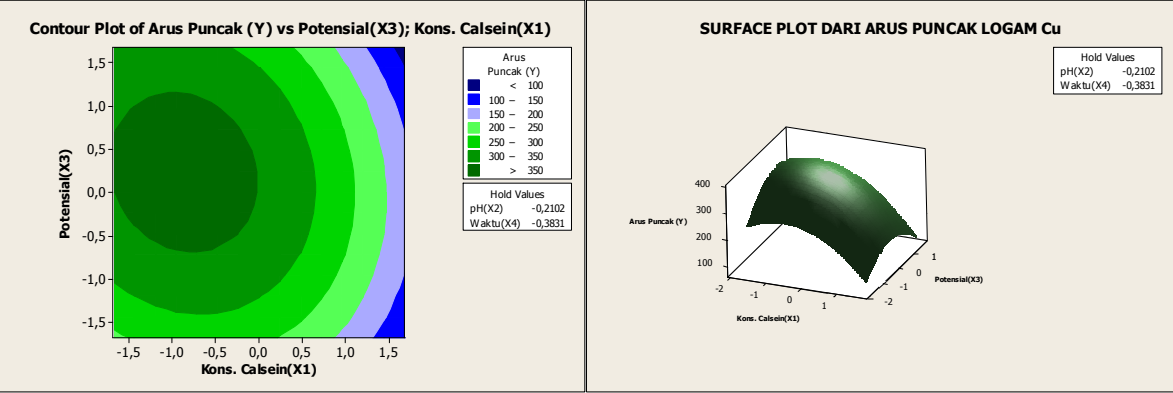

(b)

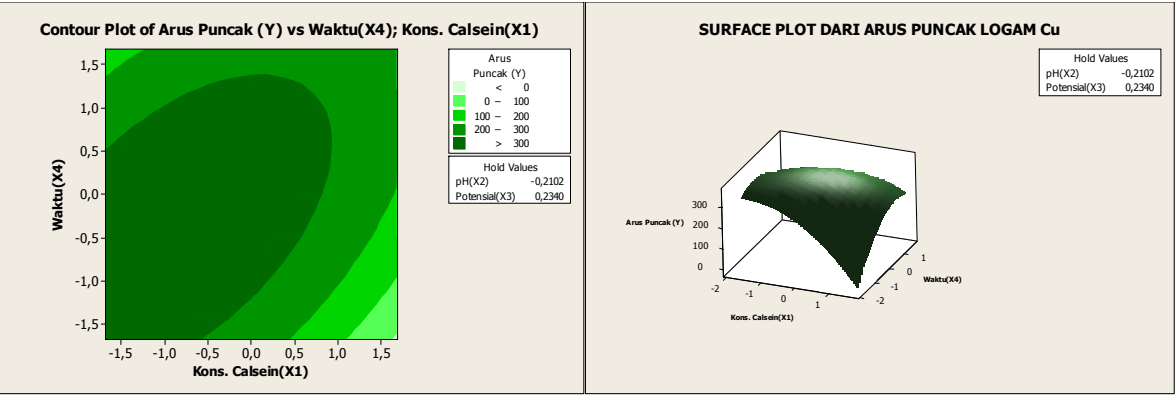

(c) 
RASĀYAN J. Chem.

Vol. 10 | No. 4 |1359-1367 | October - December | 2017

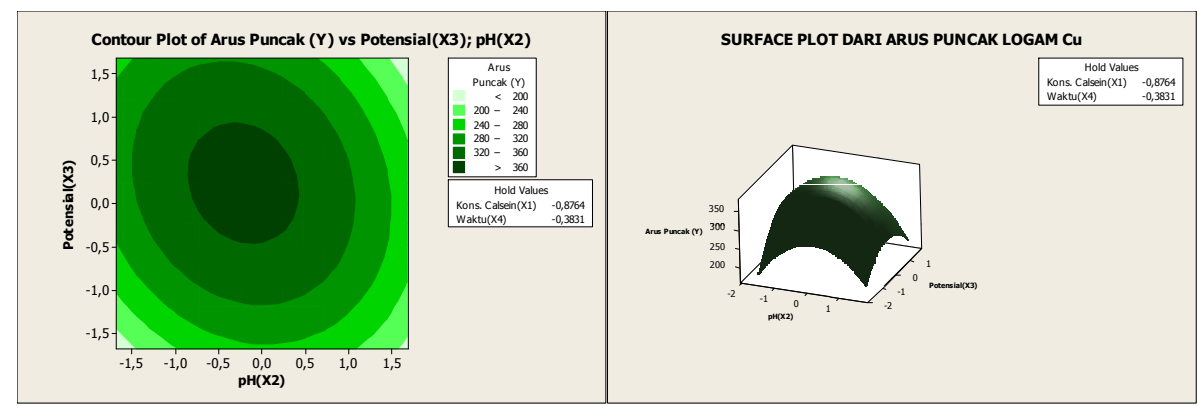

(d)

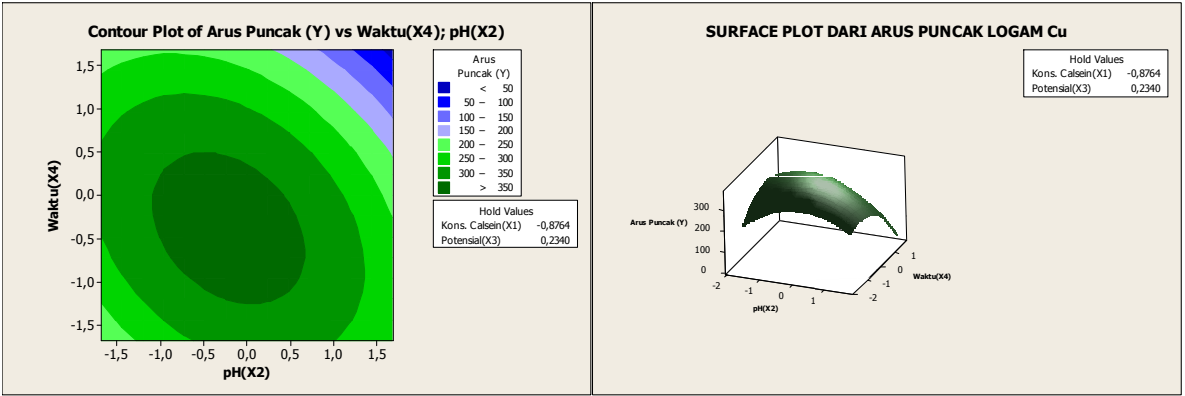

(e)

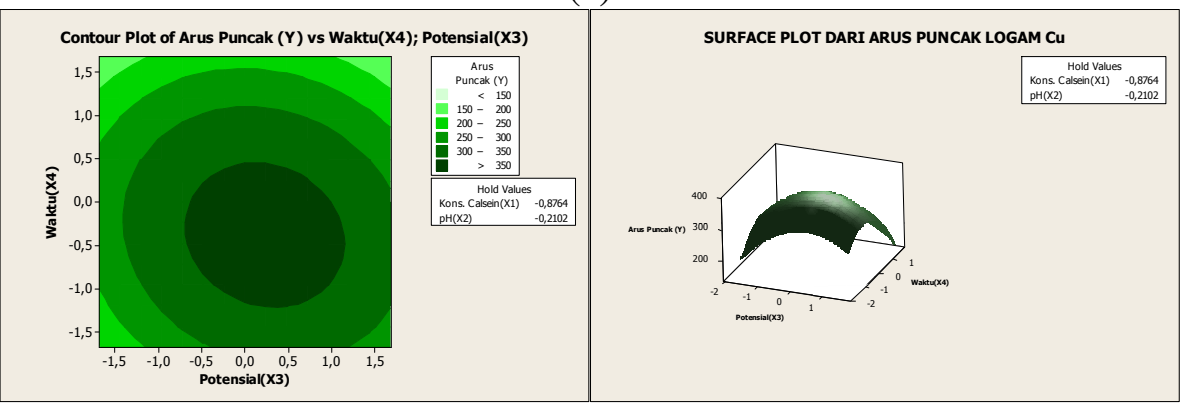

(f)

Fig.-1: Contour plots and response surface $\mathrm{Cu}$ at the point stationary

Based on Fig.-1, it can be seen the range of values of each pair of variables that allegedly will give the maximum value. As described previously, that at the stationary point obtained an optimum response value. As an alternative to achieving the optimum response value, a combination of other values can be used as shown by the innermost circle of the contour plot. All pairs of points that are in this deepest circle are expected to produce a maximum response value with the following details:

a. Each pair of points in the innermost circle of the plot between $\mathrm{x}_{3}$ and $\mathrm{x}_{4}$ will result in a predicted value of $>100$ response

b. Each pair of points in the innermost circle of the plot between $\mathrm{x}_{2}$ and $\mathrm{x}_{4}$ will produce an estimated value of $>110$ response

c. Each pair of points in the innermost circle of the plot between $\mathrm{x}_{2}$ and $\mathrm{x}_{3}$ will produce an estimated value of $>110$ response

d. Each pair of points in the innermost circle of the plot between $\mathrm{x}_{1}$ and $\mathrm{x}_{4}$ will result in a predicted value of $>100$ response

e. Each pair of points in the innermost circle of the plot between $\mathrm{x}_{1}$ and $\mathrm{x}_{3}$ will result in a predicted value of $>100$ response

f. Each pair of points in the innermost circle of the plot between $\mathrm{x}_{1}$ and $\mathrm{x}_{2}$ will produce an estimated value of $>110$ response 
RASĀYAN J. Chem.

Vol. 10 | No. 4 |1359-1367 | October - December | 2017

It can be given the choice of alternatives to generate maximum response values, there is flexibility in determining the level of each factor that is thought to be capable of generating maximum response value.

\section{Application Method}

To evaluate the validation of the proposed method for the analysis of real samples, the proposed procedure is applied to various samples such as fruit and vegetable samples (cabbage, broccoli, mustard greens, eggplant, apple, dragon fruit, melon and banana kepok). The Copper concentration in the sample can be seen in Fig.-2, and determined by the standard addition method using the recommended procedure under optimum conditions in the sample of fruit and vegetable.

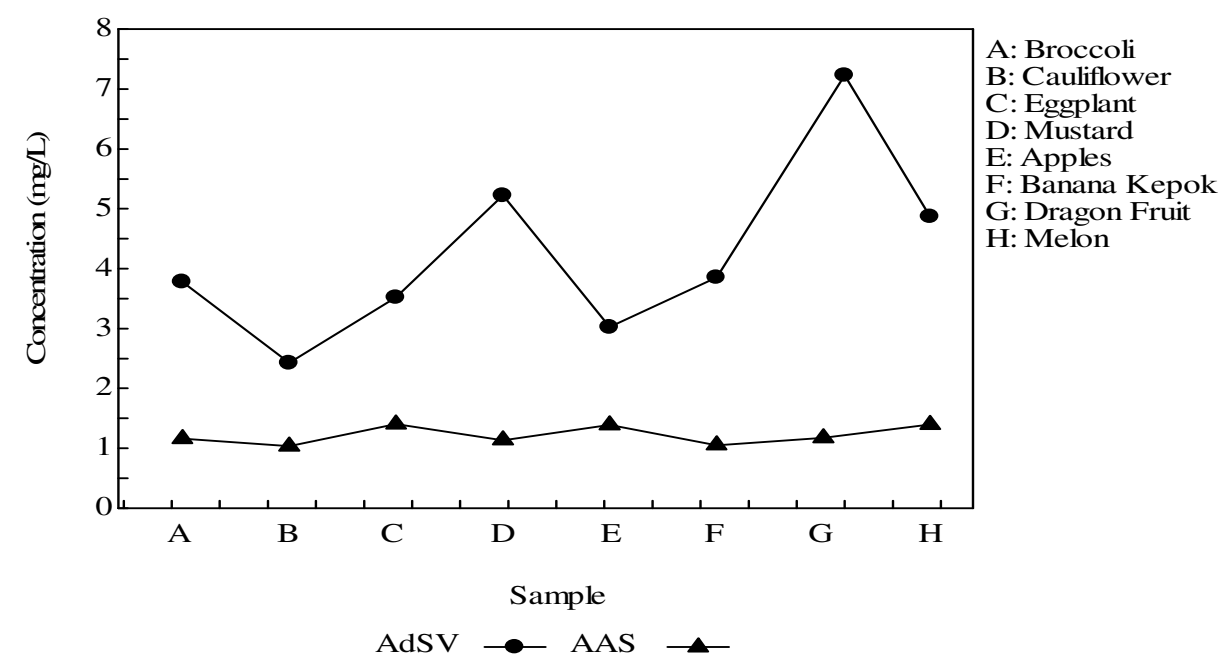

Fig.-2: Comparison AdSV and AAS in determination of copper in fruit and vegetable samples

The results from Fig.-2 show that the atomic absorption spectrophotometer (AAS) method has t calculate for each sample A; B; C; D; E; f; G; $\mathrm{H}$ is $0.10 ; 0.15 ; 0.25 ; 0.15 ; 0.20 ; 0.40 ; 0.25$ with four repetitions, and t calculate all samples smaller than t table $(2.45)$ at $95 \%(p=0.05)$, indicating the two methods are not significantly different ${ }^{34}$. Furthermore, determination of copper metal in fruit and vegetable samples in AdSV by using calcein can be seen in Table -4 .

Table -4: Determination of Copper in fruit and vegetable samples by AdSV using calcein

\begin{tabular}{c|c}
\hline Sample & $\mathrm{Cu}(\mathrm{mg} / \mathrm{L})$ \\
\hline Broccoli & 3.781 \\
\hline Cauliflower & 2.425 \\
\hline Eggplant & 3.521 \\
\hline Mustard & 5.223 \\
\hline Apples & 3.023 \\
\hline Banana kepok & 3.854 \\
\hline Dragon fruit & 7.231 \\
\hline Melon & 4.872 \\
\hline
\end{tabular}

ACKNOWLEDGMENT

The authors are grateful to Ministry of Research and Higher Education for supporting this work, April 7, 2017.

\section{CONCLUSION}

It can be concluded that the optimum condition for the determination of copper was: calcein concentration $0.11 \mathrm{mM}, \mathrm{pH} 6.8$, potential accumulation $-0.88 \mathrm{~V}$ and time accumulation $42.34 \mathrm{~s}$. The 
optimum condition obtained by value of RSD $0.74 \%$ with recovery $99.88 \%$, linear range $(0.2-110) \mu \mathrm{g} / \mathrm{L}$, and LOD $1.79 \mu \mathrm{g} / \mathrm{L}$. This CCD can be applied to the determination of copper in fruit samples (apples, dragon fruit, cantaloupe and banana kepok), and vegetable samples (broccoli, cauliflower, mustard and eggplant) effective.

\section{REFERENCES}

1. Deswati, H. Suyani and Safni, Indo. J. Chem.,12(1), 20(2012).

2. M.B. Gholivand, A. Pourhossein, M. Shahlaei. Turk. J. Chemistry. 35(4), 839 (2011).

3. N. Edgar, V. Arancibia, R. Rios, C. Rojas. Int. J. Electrochem. Sci., 7(5), 5521 (2012).

4. A. Shahryar, A. Bahirae, F. Abbasai. Food Chem., 129(3), 1274 (2011).

5. Deswati, C. Buhatika, H. Suyani, Emriadi, U. Loekman. Int. J. Res. Chem. Environ., 4(2), 143 (2014).

6. Deswati, H. Suyani, Safni, U. Loekman, H. Pardi. Indo. J. Chem.,13(3), 236 (2013).

7. N. Edgar, V. Arancibia, R. Rios, C. Rojasand, R. Segura.Talanta., 99(2), 119 (2012).

8. S.M. Danielle, D.S. Nascimento, M. Insausti, B.S.F. Band and S.G. Lemos. Fuel., 137(2), 172 (2014).

9. E. Herrero, V. Arancibia and C. Rojas. J. Elect. Anal. Chem., 729(1), 9 (2014).

10. Deswati, H. Suyani, R. Zein, A. Alif, H. Pardi. J. Chem. Pharm Res., 7(10), 833 (2015).

11. Deswati, L. Amelia, H. Suyani, R. Zein, J. Jin. Rasayan J. Chem., 8(3), 362 (2015).

12. S. Chaiyo, O. Chailapakul, T. Sakai, N. Teshima, W. Siangproh. Talanta., 108(1), 1 (2013).

13. Deswati. The development method for simultaneous determination of trace metals of $\mathrm{Cd}, \mathrm{Cu}, \mathrm{Pb}$, and $\mathrm{Zn}$ in environmental samples by adsorptive stripping voltammetry. Disertation. Andalas University (2017).

14. Deswati, E. Munaf, H. Suyani, U. Loekman, H. Pardi, Res. J. Pharm. Biol. and Chem. Sci., 5(4), 990 (2014).

15. Deswati, H. Suyani, I. Rahmi, H. Pardi. Orient. J. Chem., 33(4), 2060 (2017).

16. Deswati, E. Munaf, H. Suyani, R. Zein and H. Pardi, Asian J. Chem. 13(3),3978 (2015).

17. Deswati, H. Pardi, H. Suyani, R. Zein, and T.W. Edelw. Anal \& Bioanal. Electrochem. 8(7), 885 (2016).

18. Deswati, H. Pardi, H. Suyani, and R. Zein. Orient. J. Chem., 32(6), 3071 (2016).

19. Deswati, H. Suyani, R. Zein, A. Alif, H. Pardi. Rasayan J. Chem., 109(2), 549 (2017).

20. A.A. Ensafi, S. Abbasi, H.R. Mansour. Anal. Sci., 17(3), 609 (2001).

21. S. Zang, W. Huang. Anal. Sci.,17(4), 983 (2001).

22. R.M. Jugade, A.P. Joshi. Anal. Sci., 22(3), 571 (2006).

23. M.S. El-Shahawi., A.S. Bashammakh, A.A. Al-Shibaai, S.O. Bahaffi, E.H. Al-Gohani. Electroanal., 23(3), 747 (2011).

24. M.A. Bezerra, R.E. Santelli, E.P. Oliveira, L.S. Villar, L.A. Escaleira. Talanta. 76(4), 965 (2008).

25. G. Marcin, J. Golimowski. Anal. Chem Acta., 427(2), 55 (2001).

26. I. Paolicchi, O.D. Renedo, M.A.L. Lomillo, M.A.A. Martinez. Anal. Chem. Acta., 511(3), 223 (2004).

27. S. Yilmaz, B. Ozturk, D. Ozdemir, A.E. Eroglu, F.N. Ertas. Turk. J. Chem., 37, 316 (2013).

28. E. Espada-Bellido, M.D. Galindo-Riano, M. Garcia-Vargas. J. of Hazardous Materials. 166(4), 1326 (2009).

29. Deswati, H. Suyani, R. Zein, and H.G. Izzati Rahmi. J. Chem. Pharm. Res., 7(8), 750 (2015).

30. Deswati, I. Rahmi, H. Suyani, R. Zein, A. Alif. Rasayan J. Chem., 9(1), 8 (2016).

31. A.K. Dewi, I.W. Sumarjaya, I.G.A.M. Srinadi. E-Journal of Mathematics., 2 (2): 32 (2013).

32. Deswati, H.G. Izzati Rahmi, H. Suyani, R. Zein. J. Chem, Pharm Res., 7(10), 862 (2015).

33. Deswati, H.G. Izzati Rahmi, H. Suyani, R. Zein, A. Alif. Orient. J. Chem., 32(3), 1493 (2016).

34. J.C. Miller, J.N. Miller. Statistics for Analytical Chemistry. Ellis Horwood, New York (1994).

[RJC-1810/2017] 